\title{
Who do you think we are? The data publics in digital government policy
}

\author{
Anne L. Washington PhD \\ New York University \\ washingtona@acm.org
}

\begin{abstract}
This study provides conceptual clarity on open data users by connecting an empirical analysis of policy documents to emerging theoretical research on data publics. Releasing files to the public for reuse is the primary objective of policy on open government data. Recent public sphere scholarship provides insights into who reuses data by defining a data public as people who actively construct narratives with openly available digital sources. A content analysis of United States federal policy documents identified the language used to represent people who might reuse data. An inductive qualitative analysis of mandated digital strategy reports generated a taxonomy that characterizes people mentioned in open data policy. In addition to the taxonomy, this research contributes a set of propositions to predict data reuse based on these characteristics. The results encourage further dialog between public sphere and digital government scholars to establish testable explanations about data publics.
\end{abstract}

\section{Introduction}

Open data initiatives promoted participation and collaboration between the government and the public without conceptual clarity around who the public might be. This paper seeks to make explicit the underlying assumptions about the consumers of open data through a detailed examination of the people mentioned in United States federal open government policy.

Open data policy, as a special case of information policy [15], provides a set of guidelines for the wide dissemination of public sector information in digital formats. In 2009 United States federal agencies began to regularly release digital files, such as databases, spreadsheets, or transaction logs as open data [16] [22]. After the introduction of the 2011 Open Government Partnership, governments around the globe pledged to modernize operations through open data [31].

At the center of open data initiatives [37] is the assumption [20] that open data demand will meet the supply. In fact research has shown the opposite. Open data programs may impede reuse [35] [38] or create a barrier for wide participation [5].

Scholars recognize that open data programs are examples of socio-technical [15] digital government systems that are designed to support political and civic engagement. Socio-technical [28] research considers both human stakeholders and computational tools that jointly drive the experience of technical products. Given the complexity of establishing large technical ecosystems for open data, the past decade of open data research tracked the creation and development of infrastructure [16][22][31]. Prior research over looked individual-level attributes that inform the reuse of data. With a few earlier notable exceptions [4] [16], digital government research has less frequently engaged in questions about the people who are using open data. In the tradition of human-computer-interaction research, this analysis considers the social aspects of the open data socio-technical system. The motivation for this research is to better conceptualize the people who might use open government data.

The research question is: How are data consumers represented in open government policy? We conducted a qualitative inductive content analysis of the language in United States open data policy. United States national policy was selected for analysis because of its early leadership and because it mandated machinereadable files for oversight of its open data policy. Our analysis was significantly streamlined because the reports on open data were issued as open data. US government agencies were required to publish digital strategy reports as semi-structured files at specific websites [6].

The digital strategy reports outlined how each agency would meet broad guidelines to release machine-readable digital files. Using constant comparative method [14], we categorized the findings identifying negative cases to refine codes and support explanations of the phenomena. The breadth of the terms about data consumers ranged from professions, titles, relationships, or roles to more generic descriptions. An inductive analysis of these terms 
generated a taxonomy of the imagined public who reuses open data.

The contribution of this work is a taxonomy of data consumers that can be used in future research. The project extends previous taxonomies related to open government data [7] by elaborating on the potential of data reuse. Furthermore, a set of testable propositions provides pathways for future research. Our theoretical contribution can be classified as a "Theory of the Problem" [23] within the framework of other information systems research. Theories of the problem clarify conceptual concerns of early-stage phenomena before grand theory is developed to analyze, explain, predict, or design [11]. A theory of the problem explains how and why problems occur based on an evaluation of repeated findings in empirical evidence. This article seeks to provide a plausible explanation for barriers to open data reuse.

The findings highlight technical and subject expertise differences between people who reuse data. The themes that emerged from constant comparative qualitative coding reflect differences between insiders and outsiders, corresponding to one definition of open data [21] that emphasizes the exchange of internal files with people outside the group who originated the information. We turn to the literature on the public sphere for insights on these findings. Recent developments of the concept of a "data public" [47] provide a new lens for understanding the demand for open data.

\section{Literature Review}

Public sphere scholarship and digital government research reflect a mutual interest in the information sources that drive civic engagement. This study draws on concepts in the public sphere literature to clarify assumptions about the people who consume open government data. Recent scholarship on the public sphere provides theoretical guidance on who the public might be in the digital age.

Ruppert [47] offers the term "data public" to describe the people who reuse data and to delineate the role they serve in civic engagement. Importantly, the public sphere literature provides a means to understand not a single public but multiple publics. An overly idealized view of a unitary public sphere might unnecessary limit how open government is conceptualized and planned.

\subsection{Data Reuse}

Data reuse was a primary objective of policy that mandated the release of digital files on the Internet. The use of data was considered a natural step towards participation and collaboration. Janssen, Charalabidis, \& Zuiderwijk [7] in an early conceptual work identified this problem of technology determinacy as one of the core myths about open data. Subsequent research has confirmed the insight that building the technology is not enough to encourage use. Research on open data catalogs in the United States [54] and the United Kingdom [6] has uniformly identified low usage of available digital assets.

Charalabidis, Alexopoulos, \& Loukis [7] conducted an extensive literature review of open government data research to develop a taxonomy that reflects research ranging from management and policies, infrastructure, interoperability, to usage and value. This article expands our understanding of the usage and value of open data, the fourth aspect of their taxonomy [7].

The reuse of open data extends earlier research on barriers to e-government. Initial concerns about electronic government feared it would lead to exclusion based on demographic differences in the availability of computers [25]. The growth of smart phones and mobile Internet, according to studies [39] of the American population, dampened digital divide worries. However, concerns about demographic differences may become relevant again in determining the experience of digital participation with open data.

The ability to reuse data necessitates a wide range of technical skills [28], critical thinking skills [24], and subject matter expertise. Data files contain structured or unstructured information in a digital format. While documents represented a single perspective, data can be rearranged to find dynamic associations and unique arrangements. The skills and tools to manipulate [24] information also must come with the initiative to reshape and rethink the original order.

Information scientists refer to these abilities as forms of information labor which involve the intellectual work necessary to comprehend and use sources. Warner [34] delineates two types of information labor: syntactic labor and semantic labor.

Syntactic labor involves the ability to recognize symbols or signs. In short, this is an ability to manipulate the structure of digital files or data formats. Multiple file formats or software services are created through syntactic labor. Digital literacy and technical skills are necessary for syntactic execution.

Semantic labor, on the other hand, emphasizes the ability to transform context and meaning. This is the ability to translate content to new expressions. Knowledge organization, such as metadata or bibliographic details, is created through semantic labor. Subject matter expertise is necessary for semantic interpretation. 
Digital literacy and the digital divide bring nuance to definitions of public participation and collaboration when it involves the reuse of data.

\subsection{Open to the public sphere}

The public sphere became an influential concept after Jorgen Habermas [12] published his historical analysis of mass media. Habermas [12] imagined private people discussing matters of state based on information circulated in government documents or newspapers in "a society engaged in critical public debate". The discussions represented the Enlightenment ideal of argumentation where evidence and reasoning were more important than social status. The public sphere was not simply a public place but a conversation open to all. Technology developments have reshaped public conversations. Contemporary scholars of the public sphere reject the idea of a single public and instead argue for multiple "publics" [34]. A counter-public [3] may wish to set itself apart from the dominant discourse.

Openness to the public can be defined in multiple ways that reflects technical innovation [27] as well as democratic transparency [16]. First, open can be defined technically as releasing files, typically on the Internet, without formal rights constraints on reuse. Second, open might suggest that the organization and its operations are visible and open to scrutiny. Dissemination beyond those involved in the production of data is fundamental to understanding the concept of openness and reuse [21].

A shared understanding of openness motivates both public sphere and digital government scholars. Digital government infrastructure was built to support information-intensive social systems [27] [31]. From either perspective, openness is a perspective of sharing outwards from an internal place. Organizations [4][18] or groups [21][38] release open data for distribution to people outside the originating entity.

\subsection{The Data Public}

Digital information sources are changing civic participation and public affairs. The digital government literature explores online access as new aspect of civic obligation [4]. At the same time, public sphere scholarship explores informed civic engagement mediated through digital technology platforms [3]. A line of argument missing until recently is how unmediated information, like open data is impacting the public sphere.

The sociologist Evelyn Ruppert [47] argues that "data publics" represent the public sphere by actively witnessing the affairs of state through the lens of digital resources. Data publics construct narratives about the government by engaging and transforming digital material. For instance, the UK parliamentary released expense information as open data to encourage constituents to view how representatives spent public funds [47]. Transparency measures, like the release of parliamentary expenses, allowed journalists and individuals to publicly expose unethical behavior in the wake of a scandal.

Open data is central to constructing dominant narratives and counter-narratives [34] in the public sphere. Data publics actively use openly available digital sources to construct narratives about public affairs. If public sphere scholars are correct about multiple data publics, then government researchers might need to reassess the assumption of the public as a singular entity.

\section{Digital Government Strategy}

Digital strategy reports released by United States executive agencies are the empirical material for analyzing data publics. Strategy provides an analytic frame to assess the different implementations of open data across multiple government agencies. Strategy in management science has been defined as implicit plans, written documents, and completed actions [26]. Organizations use strategy to control their environment and meet their goals [2]. Strategy guides decisions and actions that result in an expected pattern of outcomes. Organizations who supply open data make a series of strategic management decisions that influence how and why their internal digital files are released.

For this study, the United States national digital government strategy was examined along with digital strategy reports from 25 agencies.

\subsection{US National Strategy}

In May 2012, the White House published a national digital government strategy document that served as a vision statement for open data. The "Digital Government: Building a 21st century platform to better serve the American people" [37] complemented existing executive orders and memos with a strategy for achieving digital government. The first point in the strategy was to "make open data, content, and web APIs the new default". The document continued to encourage agencies to be information-centric and customer-centric on a shared platform. Performance measurement and evaluation were components of the strategy. All government organizations subsequently were encouraged to create their own digital strategy, however only a portion [41] were mandated to publish a report. 
The mandated digital strategy report had to outline how the organization would meet national open data policy goals within the context of their mission. Office of Management and Budget (OMB) has oversight authority over US federal agencies. OMB Memorandum M-13-13 [6] mandated federal government agencies to publish a digital government strategy report. The strategy had to address plans for releasing, opening, and preparing for the automatic harvesting of metadata to a central data catalog. Each agency listed "high-value" data sets and digital services with intended release dates. For every item listed, the agency was required to describe who might use the data or service, as shown in Table 1. The resulting report had to be released at an Internet address ${ }^{1}$ that included the agency domain name and a specific file name.

Table 1: Digital strategy report excerpts

\begin{tabular}{|l|l|}
\hline $\begin{array}{l}\text { Census API } \\
\text { (Commerce) }\end{array}$ & $\begin{array}{l}\text { Economic and demographic data } \\
\text { Scope: external } \\
\text { Main Customer: Users of economic and } \\
\text { demographic data such as realtors, } \\
\text { economic professionals }\end{array}$ \\
\hline $\begin{array}{l}\text { National } \\
\text { Archives } \\
\text { (Archives) }\end{array}$ & $\begin{array}{l}\text { Make National Archives records } \\
\text { available through Flickr } \\
\text { Scope: external } \\
\text { Main Customer: general public, } \\
\text { historians, students }\end{array}$ \\
\hline $\begin{array}{l}\text { Alternative } \\
\text { fueling } \\
\text { station } \\
\text { location data } \\
\text { (Energy) }\end{array}$ & $\begin{array}{l}\text { This data set is considered the most } \\
\text { trusted industry resource. } \\
\text { Scope: both (external \& internal) } \\
\text { Main Customer: Owners and operators } \\
\text { of alternatively fueled vehicles }\end{array}$ \\
\hline
\end{tabular}

Reports explicitly stated intended data customers.

\subsection{Agency Strategy Reports}

OMB required agencies to produce digital strategy reports if they were under the oversight authority of Public Law 101-152 [41], the Chief Financial Officers (CFO) Act of 1990. OMB required the $25 \mathrm{CFO}$ Act agencies, as shown in Table 2, to create a digital strategy. Only a few agencies continued to update their digital strategies beyond the initial December 2013 deadline.

Digital strategy reports had to specify new digital services or improvements to existing services. Agencies were required to identify at least two significant data sets or systems and release them within 12 months [37]. With a mandate for customer-centric

\footnotetext{
${ }^{1}$ e.g. http://www.treasury.gov/digitalstrategy.xml
}

information [6], the agency had to describe the main customers for every service or data set listed in the report. Table 1 contains excerpts about intended data consumers from a few digital strategy reports.

Uniquely, United States policy mandated that the digital strategy reports be released as machine-readable open data files. We leveraged this open data advantage in our research design. The digital strategy reports were written in XML, eXtended Markup Language, a semi-structured language regularly used to provide structure to documents and regularly used in digital government [30]. XML organizes language into logical sections using mark-up code. Meaningful codes make it easier to parse intellectually and computationally. For instance the label "main customer" identified who was the intended user for the data set or service. The semi-structured aspect of the reports also made it possible to compare specific sections across multiple government agencies.

The national digital strategy document was published 18 months before the deadline for agency strategy reports. In order to understand the connections between the national strategy and the agency strategies, we completed a separate content analysis of the national digital strategy [37]. The findings below reflect an analysis of the 2012 Obama administration national open data strategy and 2013 strategies of individual federal agencies.

Table 2: United States federal agencies

\begin{tabular}{ll}
\hline 1 Archives & 14 Air and Space \\
2 Commerce & 15 Nuclear \\
3 Defense & 16 Personnel Management \\
4 Homeland Security & 17 Small Business \\
5 Interior & 18 Securities \\
6 Labor & 19 Social Security \\
7 Education & 20 State \\
8 Energy & 21 Transport \\
9 Environment & 22 Treasury \\
10 Government Services & 23 International Aid \\
11 Health & 24 Agriculture \\
12 Housing & 25 Veterans Affairs \\
13 Justice &
\end{tabular}

These 25 CFO-Act agencies are analyzed in the study.

\section{Methods}

The study leveraged the machine-readable digital strategy reports in the investigation. The research question asked how data consumers are represented in open government policy.

Computational tools augmented inductive coding as in other digital government content analysis projects [31] [36]. Content analysis [19], a cross-disciplinary method, systematically supports making inferences 
from texts or other primary sources. The digital strategy reports were first processed computationally as XML files and then analyzed using a qualitative inductive content analysis. The XML digital strategy reports were stripped to the relevant units that addressed how the public would use digital assets. The XML structure made it possible to easily isolate words about specific services or data sources.

\subsection{Research Design}

The research is designed to clarify theoretically distinct categories about data publics [29] grounded in information systems and public sphere theory. The goal of the research design was to expand the definition of an open data consumer with direct "in vivo" [32] language used in public policy. The research design builds a taxonomy and then leverages its characteristics to reflect on the people who use open data. A set of propositions poses hypotheses that could improve the reuse of open data based on the characteristics of data publics.

There are several limitations to this study. The empirical context considers only one country: the United States. Because of the interest in establishing the construct of a data public, we think this focus on one geo-political location will support our inductive exploration. We attempted to mitigate the potential bias of inductive research by having multiple people review the analysis and by conducting regular peerdiscussions on the findings. Finally, the range of evidence is limited to one source of documents. The variation comes not from different sources but from the way that different agencies respond within this document genre.

\subsection{Data Collection}

The national digital strategy document [37] was 78 $\mathrm{KB}$ in text format, contained 1,328 lines and 11,349 words. It was available as a web page and as a digital PDF document. The text used in the study is from a transformation of the PDF document.

The agency strategy reports in XML were 1.2 MB and contained 29,741 lines and 141,131 words including all markup tags. The text version of all 25 federal agency reports was $652 \mathrm{~KB}$ and contained 93,549 words. Together the 26 documents analyzed contained 152,480 words.

Each agency had to list at least two systems and data sets in the report by specifying the following: Name of system, Description of system, Scope of system (internal and external), Main Customer. See Table 1 for some examples. The sections from the agency reports used in the study are $2.1-2.2$ about data sets and $7.1-7.2$ about digital services.

- $\quad$ Section 2.1 "Engage with customers to identify at least two existing major customer-facing services that contain high-value data or content"

- $\quad$ Section 2.2 "Make high-value data and content in at least two existing major customer-facing systems available through web APIs, apply metadata tagging"

- Section 7.1 "Engage with customers to identify at least two existing priority customer-facing services to optimize for mobile use"

- Section 7.2. "Optimize at least two existing priority customer-facing services for mobile use and publish a plan for improving additional existing services"

\subsection{Data Analysis}

The terms that appeared in open data policy documents were coded [14] using constant comparative methods to understand the use and distribution of language [10]. Negative cases [32] were used to refine codes and support explanations of the phenomena. We incorporated word frequencies with traditional comparison methods of inductive research. These procedures established the necessary objective distance from the data while still benefitting from the close readings [14] necessary for good qualitative reasoning.

The most frequent terms about people who reuse data were generic such as "Researchers" or "Innovators". The remaining list has a depth of unique descriptions that describe roles, job titles, and experience, such as Records Managers, Veterans, First responder, Survivors, Caregivers, or Software Developers.

The agency reports were not uniformly written so term frequency was not a significant measure. Several agencies chose one definition for all the services and data they released so those phrases were repeated for each dataset described. Other agencies submitted more than the required sources also skewing the appearance of their customer terms. We provide some of the word counts here because they are instructive about repetition yet the focus of this analysis is the breadth of possible terms to describe users.

\section{Findings}

The content analysis identified 51 unique terms for individuals and 45 unique terms for organizations that appeared across all 26 documents analyzed. Because we were attempting to understand the wealth of people 
who use data, we identified characteristics of all terms found. The characteristics described in the findings below make distinctions about the locus of action.

The characteristics are scale, relation to the organization, and expertise. The first characteristic, scale, asks: who is acting? The second characteristic, relationship, asks: are these people internal or external to the original organization? The third characteristic, expertise, asks: what skills are implied?

\subsection{Scale}

The first characteristic distinguishes between individuals and organizations. One individual controls a different span than a group or organization [26]. An individual with a title may have some autonomy within an organization however for clarity of purpose, they are categorized as acting independently.

5.1.1 Individual. The individual category refers to specific roles or titles mentioned in the documents, such as "Chief Information Office" or "teacher". Tables 3,4 , and 5 present the 51 terms for individual people identified in the documents.

5.1.2 Organization. The organization category refers to groups with any institutional support or infrastructure such as "Congress" or "The Military". There were 45 terms for organizations that included Tribal governments, Law enforcement, Civilian workforce, Data Service Team, Federal Web Managers Council, Businesses, Financial institutions, and States.

\subsection{Relationship to the organization}

The notion of insiders and outsiders is fundamental to understanding the reuse of data [21] and the structure of the agency reports [6]. The policy mandated that the agency specify whether each item would support internal customers or external customers. The second characteristic reflects the data consumer's relation to the organization.

5.2.1 Internal. The internal category refers to people who were associated with a specific federal job title, such as "Enterprise Architect". In addition, close reading of sections about organizational operations includes descriptions of people such as "internal stakeholders".

5.2.1 External. The external category refers to people outside the organization or group that supplied the data. The external category represents other parts of the federal government, local or state government. The public sector or private persons are also associated with this category. External descriptions include "borrowers" or "private lenders".
Table 3: Individuals with syntactic expertise

\begin{tabular}{|c|c|}
\hline Internal & $\begin{array}{ll}\text { - } & \text { Chief Information Officer } \\
\text { - } & \text { Chief Innovation Officer } \\
\text { - } & \text { Chief Technology Officer } \\
\text { - } & \text { Data Steward } \\
- & \text { Inforprise Architect } \\
- & \text { Privacy Officers } \\
- & \text { Records Managers } \\
- & \text { Web Managers }\end{array}$ \\
\hline External & $\begin{array}{ll}\text { - } & \text { Data customers } \\
\text { - } & \text { Data owners } \\
\text { - } & \text { Data users } \\
\text { - } & \text { Developers (software) } \\
\text { - } & \text { Innovaty adopters } \\
\text { - } & \text { Mobile workforce } \\
\text { - } & \text { Smartphone users } \\
\text { - } & \text { Technical users }\end{array}$ \\
\hline
\end{tabular}

Table 4: Individuals with semantic expertise

\begin{tabular}{|l|l|}
\hline Internal & - Federal employees \\
& - Senior leaders \\
& - Staff members \\
& - Internal stakeholders \\
\hline External & - Advocates \\
& - Bank partners \\
& - Borrowers \\
& - Caregivers \\
- Education professionals \\
- Diplomat \\
- Energy professionals \\
- Entrepreneurs \\
- First responders \\
- Healthcare professionals \\
- Job creators \\
- Non-technical users \\
- Physicians \\
- Policy makers \\
- Private lenders \\
- Researchers \\
- Stakeholders \\
- Subject matter experts \\
- Survivors \\
- Therapists \\
- Teachers \\
- Veterans \\
- Victims \\
\end{tabular}


Table 5: Individuals without specific expertise

\begin{tabular}{|l}
\hline - \\
- Citizens \\
- Community \\
- Emstomer \\
- Residents \\
\hline
\end{tabular}

\subsection{Expertise}

Open data requires skills to both manipulate the files and to understand the context. The third characteristic recognizes that some people have syntactic skills in working with data formats while others may have semantic or subject-matter expertise. Syntactic skills and semantic skills are two opposing types of information labor [34] that in many cases may not be present in the same individual. This characteristic emphasizes the need for understanding both the content and the format to truly leverage open data assets. Of course, there were some people described who had neither semantic nor syntactic expertise.

5.3.1 Semantic. The category of semantic expertise represents knowledge of the topic or familiarity with a specific experience. While these people may have expert knowledge about what the agency does, they may not understand how to accomplish technical tasks. Semantic examples included "health care professional" or "caregiver".

5.3.2 Syntactic. The category of syntactic expertise represents technical skill and ability. While these people may be familiar with how to parse a data file using advanced computational methods, they may not be familiar with the content within the document. Syntactic examples included "technical users" or "web managers".

5.3.3 Generic. The category of generic expertise represents no given experience or ability. These are people who have no specific skill but may have a general interest. This category best mirrors Habermas [12] idea of private people with an interest in public debate. Some items, such as "Residents" or "Citizens" do not suggest either semantic or syntactic expertise.

\subsection{A taxonomy of data publics}

The taxonomy organized the terms into three characteristics of data consumers:

1. Scale: individuals/organizations,

2. Relationship: internal/external,

3. Expertise: semantic/syntactic.
The analysis of US digital government strategy suggests that there can be multiple data publics. These characteristics are analytically distinct but may naturally intersect. For instance internal syntactic publics might understand the idiosyncrasies of the production of data assets but also have expertise as employees [31]. External syntactic publics may gain semantic knowledge by participating in civic hack-athons [38]. Future research might design an experimental study to investigate the tensions between individuals/organizations, internal/external, or semantic/syntactic. Further testing of these dichotomies might explain why a data catalog designed to support everyone, actually serves no one.

The analysis makes a contribution to practice by providing a listing of potential data publics. These findings give federal policy-makers an opportunity to learn more about the range of data publics served across multiple agencies. The findings suggest that more than one data public was imagined in the original United States open data policy.

\section{Discussion}

The terms in the agency reports and the national open data policy reflected a difference in mindset. The 2012 national digital government strategy contained generic descriptions such as "citizens". Agency reports were more specific such as "First Responders". Furthermore, some words representing concepts that appeared often in agency reports, such as entrepreneurs, were rare in the national report. In other cases the national and agency reports differed by which form of the word they emphasized. The national policy used the term innovation while the agency policy focused on innovators. The findings suggest that the originating national policy and the agency reports had different conceptualizations of the public.

Open data are available to the general public but each file released is not for everyone. Although open data initiatives continue information policy for government information, these empirical findings demonstrate that open data is different from government information. Government information is designed to accommodate the maximum number of people. Data files must be targeted to very specific consumers who have an interest or familiarity with the files.

\section{Propositions}

The concept of "data publics" provides a framework for thinking through the needs of people with varying combinations of characteristics. Data publics who are familiar with data syntax and 
processing are likely to have advantages in using and manipulating data but perhaps lack an ability to understand the subject matter. This leads us to suggest that data publics who are strong in syntax or strong in semantics might need different types of support.

- $\quad$ Proposition 1: Semantic data publics would need additional support in identifying appropriate file formats in a data catalog.

- Proposition 2: Syntactic data publics would need additional support in interpreting appropriate knowledge organization in a data catalog.

The range of internal users noted in the digital strategy reports points to an important implication of open data. The data supply organization can benefit from the release of open data when these products are leveraged for internal services and data needs [18]. The strategy documents recognized the importance of institutional use by using words about "interoperability" and "inter-agency". In fact, the internal syntactic groups are likely to have both strong technical and semantic abilities because they already are familiar with the subject area.

- Proposition 3: Internal syntactic publics will need less knowledge organization than external publics.

Finally, some data publics represented in the data are clearly organizational consumers of data. Organizations, such as "local government" or "military", might have collective resources [28] that can help with difficulties in understanding syntax or semantics. The differences between individual and organizational data consumers might have an impact on how they approach open data resources.

- Proposition 4: Publics that represent individuals have fewer resources to learn how to use open data than organizational ones.

The propositions present a path towards deepening an understanding of data reuse from the perspective of multiple publics. The propositions further the contribution of this research by offering testable explanations about why or how data publics function. As a theory of the problem [34], this taxonomy of data publics could be used to predict the likely success or failure of a design that incorporates the taxonomy categories. Designers and policy makers should consider how they want to instruct agencies to meet the needs of specific constituencies.

Once data is released to the public, there are few mechanisms for calling it back or knowing exactly how it was used. Additionally, privacy concerns limit the amount that governments track their data sets. While some academics use data citation methods for sharing research [1], these methods are not widely practiced for non-scientific open data.

\section{Conclusion}

Open government data programs, established nearly a decade ago, are a stable aspect of how governments do business. Data suppliers now need additional tools to conceptualize the individuals and organizations who reuse open government data.

This paper addressed who is the data public with an analysis of United States digital government policy. The characteristics of data publics provide a more precise view of the people who reuse open data. This new knowledge gives digital government scholars avenues for research on human factors in the design of open data infrastructure.

One data public does not fit all. The evidence presented here questions the assumption that there is a unitary public sphere for open data and suggests productive lines of research between public sphere and digital government scholars.

\section{References}

[1] Altman, M. et al. 2013. Out of Cite, Out of Mind: The Current State of Practice, Policy and Technology for Data Citation. Data Science Journal. 12, (2013), 1-75.

[2] Bakos, J.Y. and Treacy, M.E. 1986. Information Technology and Corporate Strategy: A Research Perspective. MIS Quarterly. 10, 2 (1986), 106.

[3] Baym, N.K. and boyd, danah 2012. Socially Mediated Publicness: An Introduction. Journal of Broadcasting \& Electronic Media. 56, 3 (Jul. 2012), 320-329.

[4] Bertot, J.C. 2006. User-centered e-government: Challenges and benefits for government Web sites (an editorial). Government Information Quarterly. 23, 2 (2006), 163-8.

[5] Bright, J. et al. 2015. Explaining Usage Patterns in Open Government Data: The Case of Data.Gov.UK. ICPP International public policy association conference proceedings (Jun. 2015).

[6] Burwell, S. et al. 2013. Open Data Policy-Managing Information as an Asset Memo M-13-13. Office of Management and Budget, Executive Office of the President (May 9 2013)

[7] Charalabidis, Y. et al. 2016. A taxonomy of open government data research areas and topics. Journal of Organizational Computing and Electronic Commerce. 26, 12 (Apr. 2016), 41-63.

[8] Dawes, S.S. 2009. Governance in the digital age: A research and action framework for an uncertain future. Government Information Quarterly. 26, 2 (Apr. 2009), 257264.

[9] Delcambre, L. and Giuliano, G. 2005. Digital government research in academia. Computer. 38, 12 (Dec. 2005), 33-39. 
[10] Fleischmann, K.R. et al. 2015. Thematic Analysis of Words that Invoke Values in the Net Neutrality Debate. iConference 2015 Proceedings. (Mar. 2015).

[11] Gregor, S. 2006. The Nature of Theory in Information Systems. MIS Quarterly. 30, 3 (Sep. 2006), 611-642.

[12] Habermas, J. 1991. The structural transformation of the public sphere: an inquiry into a characteristic of bourgeois society. MIT Press.

[13] Harrison, T.M. et al. 2012. Creating Open Government Ecosystems: A Research and Development Agenda. Future Internet. 4, 4 (Oct. 2012), 900-928.

[14] Holliday, A. 2007. Doing and writing qualitative research. Sage Publications.

[15] Jaeger, P.T. 2007. Information policy, information access, and democratic participation: The national and international implications of the Bush administration's information politics. Government Information Quarterly. 24, 4 (2007), 840-859.

[16] Jaeger, P.T. and Bertot, J.C. 2010. Transparency and technological change: Ensuring equal and sustained public access to government information. Government Information Quarterly. 27, 4 (Oct. 2010), 371-376.

[17] Janssen, M. et al. 2012. Benefits, Adoption Barriers and Myths of Open Data and Open Government. Information Systems Management. 29, 4 (Fall 2012), 258-268.

[18] Jurisch, M.C. et al. 2015. An International Survey of the Factors Influencing the Intention to use Open Government. 2015 48th Hawaii International Conference on System Sciences (hicss) (Los Alamitos, 2015), 2188-2198.

[19] Krippendorff, K. 2004. Content analysis : an introduction to its methodology. Sage.

[20] Krishnamurthy, R. and Awazu, Y. 2016. Liberating data for public value: The case of Data.gov. International Journal of Information Management. 36, 4 (Aug. 2016), 668-672.

[21] Leonelli, S. 2013. Why the Current Insistence on Open Access to Scientific Data? Big Data, Knowledge Production, and the Political Economy of Contemporary Biology. Bulletin of Science, Technology \& Society. 33, 1-2 (Feb. 2013), 6-11.

[22] Luna-Reyes, L.F. et al. 2014. Open Government, Open Data and Digital Government. Government Information Quarterly. 31, 1 (Jan. 2014), 4-5.

[23] Markus, M.L. 2014. Maybe not the king, but an invaluable subordinate: a commentary on Avison and Malaurent's advocacy of 'theory light' IS research. Journal of Information Technology. 29, 4 (Dec. 2014), 341-345. [24] Min, S.-J. 2010. From the Digital Divide to the Democratic Divide: Internet Skills, Political Interest, and the Second-Level Digital Divide in Political Internet Use. Journal of Information Technology \& Politics. 7, 1 (Feb. 2010), 22-35.

[25] Murray, M.C. and Pérez, J. 2014. Unraveling the Digital Literacy Paradox: How Higher Education Fails at the Fourth
Literacy. Issues in Informing Science and Information Technology (IISIT). 11, (2014), 85-100.

[26] Oliver, C. 1991. Strategic Responses to Institutional Processes. The Academy of Management Review. 16, 1 (Jan. 1991), 145-179.

[27] Pardo, T.A. et al. 2012. E-Government Interoperability Interaction of Policy, Management, and Technology Dimensions. Social Science Computer Review. 30, 1 (Feb. 2012), 7-23.

[28] Racherla, P. and Mandviwalla, M. 2013. Moving from Access to Use of the Information Infrastructure: A Multilevel Sociotechnical Framework. Information Systems Research. 24, 3 (2013), 709-730.

[29] Ruppert, E. 2015. Doing the Transparent State: open government data as performance indicators. A World of Indicators: The making of governmental knowledge through quantification. Cambridge University Press. 127-150.

[30] Salminen, A. 2005. Building Digital Government by XML. HICSS Hawaii International Conference on System Sciences (2005), 122b.

[31] Sayogo, D.S. et al. 2014. A Framework for Benchmarking Open Government Data Efforts. 47th Hawaii International Conference on System Sciences (HICSS) (New York, 2014), 1896-1905.

[32] Van den Hoonaard, W.C. 1997. Working with sensitizing concepts : Analytical field research. Sage Publications.

[33] Warner, J. 2005. Labor in information systems. Annual Review of Information Science and Technology. 39, 1 (2005), 551-573.

[34] Warner, M. 2002. Publics and counterpublics. Zone Books ; Distributed by MIT Press.

[35] Washington, A.L. and Morar, D. 2016. Open for Whom? An Overview of Data.Gov File Formats. Technical Report \#ID 2770925. Social Science Research Network. [36] West, D.M. 2005. Digital government : technology and public sector performance. Princeton University Press.

[37] White House 2012. Digital Government. Building a 21st century platform to better serve the American people. Obama Administration.

[38] Young, M. and Yan, A. 2017. Civic Hackers' User Experiences and Expectations of Seattle's Open Municipal Data Program. Proceedings of the 50th Hawaii International Conference on System Sciences (2017).

[39] Zickuhr, K. and Smith, A. 2012. Digital differences. Pew Research Center: Internet, Science \& Tech.

[40] Zuiderwijk, A. et al. 2012. Socio-technical impediments of open data. Electronic Journal of eGovernment. 10, 2

(2012), 156-172.

[41] 1990. Chief Financial Officers (CFO) Act Public Law 101-576. 